\title{
Preliminary notes on the conservation status of Baird's tapir Tapirus bairdii in north-eastern Honduras
}

\author{
Kevin Flesher
}

\begin{abstract}
Between April and August 1994, three steps were taken to assess the status of Baird's tapir Tapirus bairdii in north-eastern Honduras: (i) forest cover was mapped to estimate the amount of habitat available; (ii) interviews with local people were conducted to determine where the species occurs; and (iii) searches were made for tapir signs in several mountain ranges to corroborate interview information. Local reports and searches indicated that the species occurred in forests throughout the area. Using density estimates of $0.05-$ 0.24 tapirs per sq $\mathrm{km}$, there may be $520-2760$ tapirs in the $10,400-11,500 \mathrm{sq} \mathrm{km}$ of contiguous rain forest that remains in north-eastern Honduras-a population large enough to have a good chance of long-term persistence. The main threat to the population is human
\end{abstract}

\section{Introduction}

The conservation of Baird's tapir Tapirus bairdii is becoming increasingly a problem of space. The demand for land by farmers, ranchers, loggers and other developers has cut deeply into Central America's wildlands and, given the burgeoning human population of the region, these pressures are unlikely to abate (Myers, 1986). Baird's tapir once occurred throughout the Central American rain-forest biome with a continuous distribution from Mexico to Ecuador. Now, populations have become fragmented as large tracts of forest have disappeared, and the species has been classified as Vulnerable (IUCN, 1996). The species's best hope for survival is now tied to the fate of the few remaining large forest blocks. One of the largest of these blocks covers an extensive area in north-eastern Honduras and northern Nicaragua (Fig. 1). The objectives of this study were to determine if Baird's tapir still occurs in the forests of north-eastern Honduras, to make a rough estimate of the population's size and to determine the factors threatening tapir persistence.

Kevin Flesher Biotech Center/Foran Hall, Room 135, 59 Dudley Road, New Brunswick, NJ 08901, USA.

E-mail: kevinflesher@yahoo.com colonization, which is destroying the forest along the rivers and major streams. This is fragmenting the tapit population into isolated units, which will be increasingly subject to the stochastic events that drive smal populations to extinction. Hunting, which along witr habitat destruction, is a major contributor to the rapid decline of tapir populations in areas of human colonization, does not appear to pose an immediate threat in the study area. However, population trend data are lacking and the impact of hunting on tapirs remains unassessed.

Keywords Baird's tapir, colonization front, conservation, habitat fragmentation, Honduras, Tapirus bairdii, viable populations.

\section{Study area}

The rain forests of north-eastern Honduras are located in the departments of Olancho, Colon and Gracias a Dios $\left(84^{\circ} 37^{\prime}-86^{\circ} 00^{\prime} \mathrm{W}, 14^{\circ} 00^{\prime}-16^{\circ} 00^{\prime} \mathrm{N}\right.$; Figs 2 and 3$)$. This is a rugged area dominated by a series of steep mountain ranges, mostly between 400 and $900 \mathrm{~m}$ in elevation but reaching a maximum of $2354 \mathrm{~m}$. Tropical broad-leaved evergreen rain forests cover most of the mountain slopes, while agricultural/pastoral lands occupy the three major valleys: Agalta, Guayape and Sico. Pine savannahs and semi-deciduous woodlands occur along the lower mountain slopes and low hills in the Agalta and Guayape valleys. Five major riversRio Tinto, Pio Paulaya, Rio Platano, Rio Patuca and Rio Coco-flow through these mountains, all fed by innumerable creeks and streams, which characterize this region of abundant water. Most of the more than $2000 \mathrm{~mm}$ of yearly precipitation falls between May and October. The temperature ranges between 21 and $32^{\circ} \mathrm{C}$.

To the north-east of the rain-forest area lie the extensive pine savannahs and swampy lowlands of Mosquitia, while to the west and south lie pine-covered mountain ranges that characterize much of the Honduran landscape. 


\section{Methods}

The study was conducted between April and August 1994, with a total of 41 days spent in the field. Several methods were used to accomplish the study's objectives.

\section{Potential tapir habitat}

The extent of forest cover was mapped as accurately as possible to determine how much potential tapir habitat exists. This was done by hiking and driving throughout much of the Agalta, Malacate, Carbon, Rio Tinto, Paya, Punta Piedra and Esperanza ranges, and drawing forest boundaries on 1:50,000 topographic maps using natural landscape features as reference points. The extent of forest cover for the areas not visited (Patuca, Platano, Entre Rios and Colon ranges) was drawn based on conversations with farmers, missionaries, soldiers, merchants and expatriates familiar with these areas, and from the forest estimates listed in the Corporacion Hondurena de Dessarrollo Forestal (COHDEFOR)/Peace Corps/Honduran Tourist Agency map of Honduras's protected areas. Once mapped, forest cover was estimated by counting the $1-\mathrm{sq}-\mathrm{km}$ pixels that fell within the forest boundaries. Pixels with partial forest cover were assigned to three categories $(0.25,0.50$ and $0.75 \mathrm{sq} \mathrm{km})$ and counted. Forest estimates for the areas not visited are less accurate.

\section{Distribution and numbers of tapirs}

Two techniques were employed to determine the presence or absence of tapirs in an area: collecting anecdotal information and searching for signs of tapirs.

\section{Anecdotal information}

Most information was collected through informal interviews with farmers I stayed with or met while hiking along
Fig. 1 The remaining fragments of the Neotropical rain-forest biome. The study area in Honduras is indicated by the box. Map modified from Emmons \& Freer (1997).

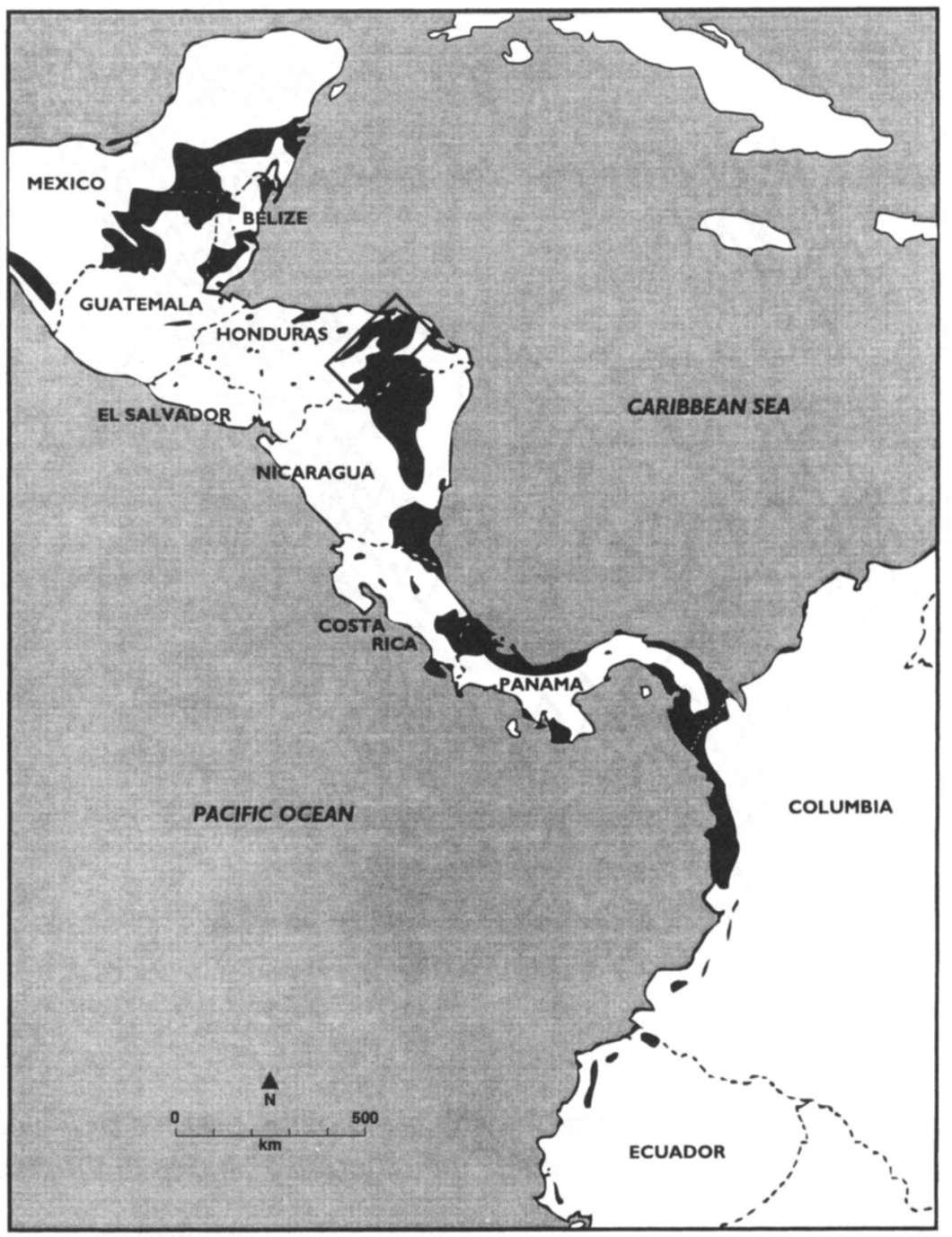




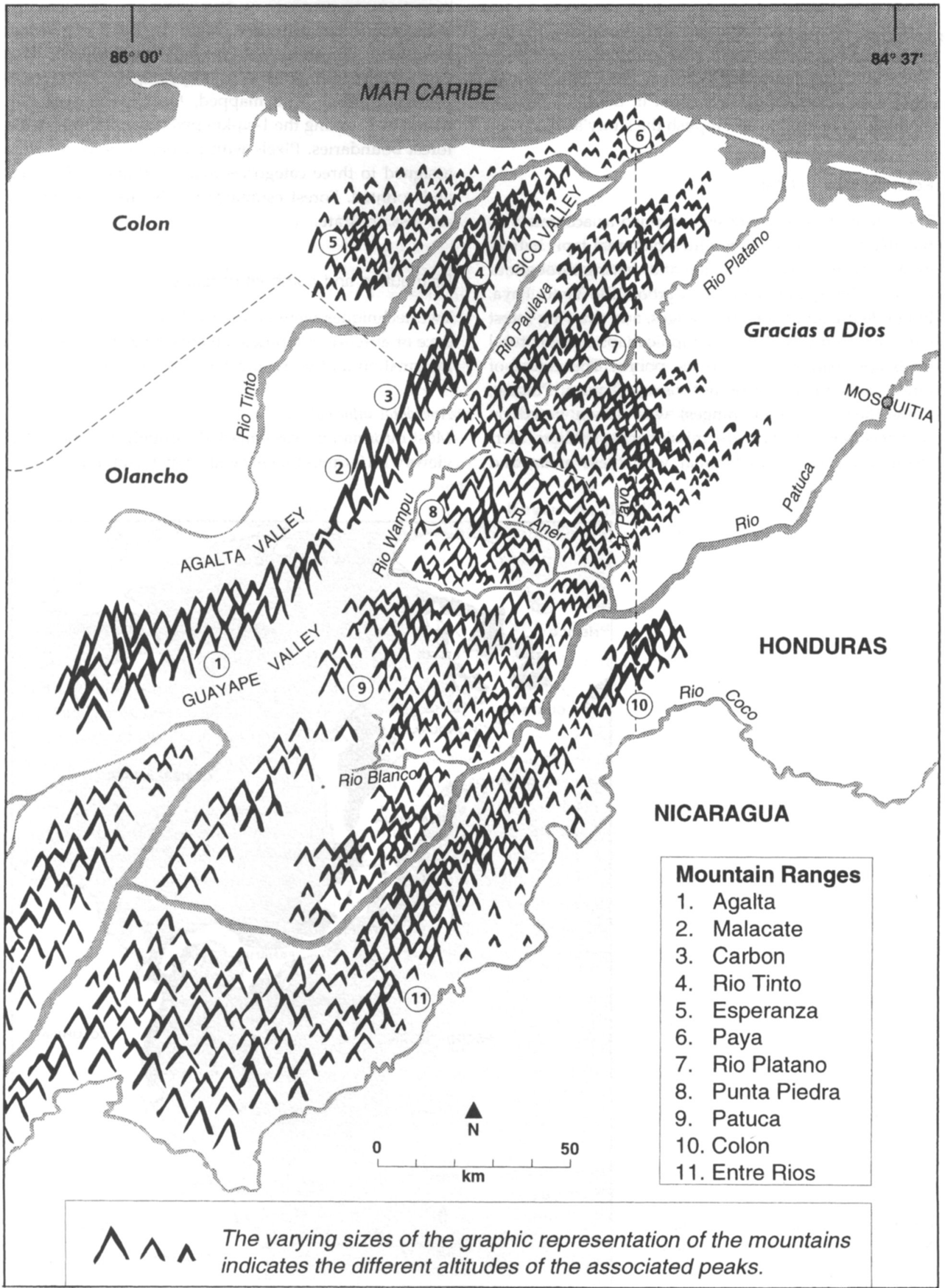

Fig. 2 The major rivers, valleys and mountain ranges of north-eastern Honduras. 


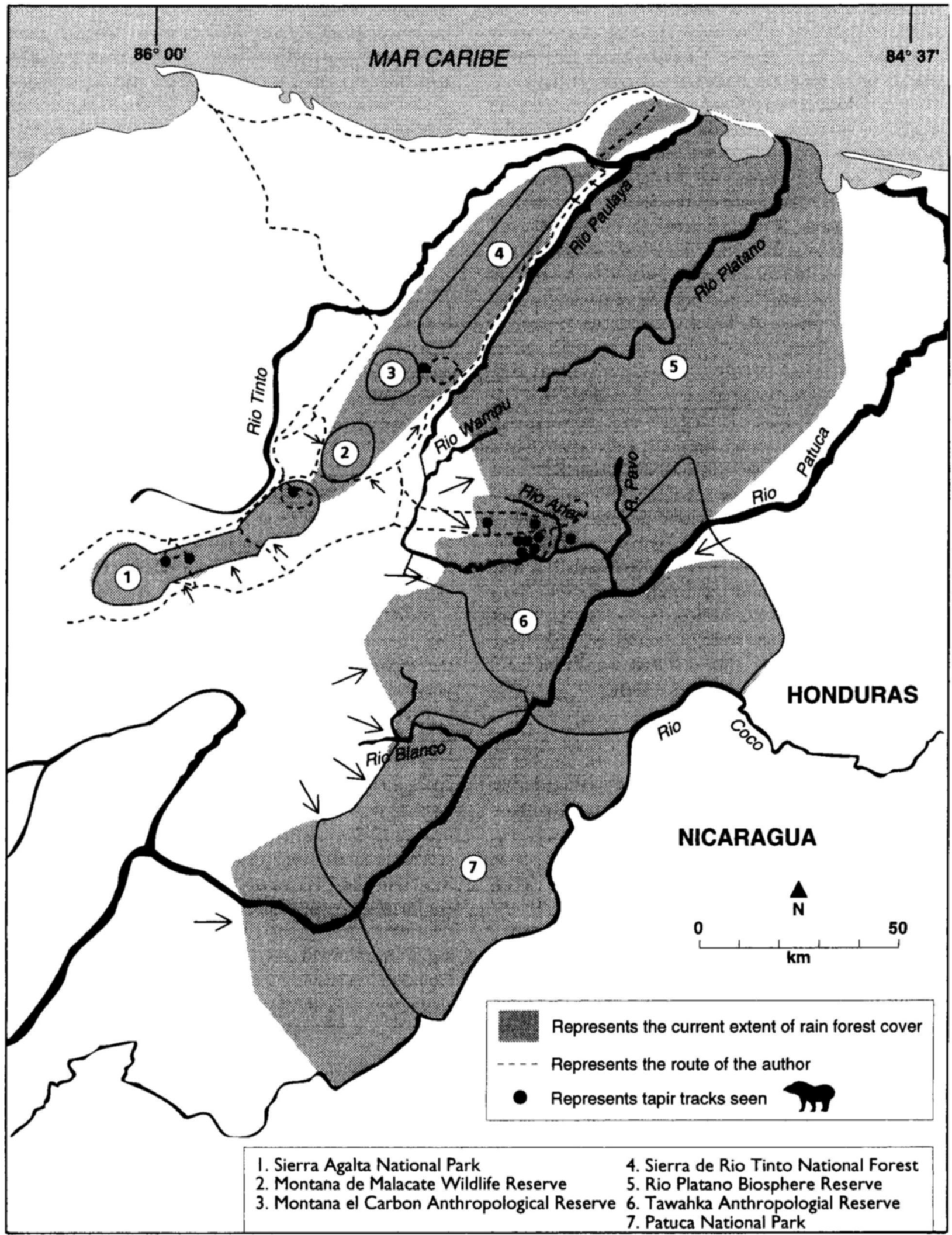

Fig. 3 The current extent of rain-forest cover and the proposed reserve network in north-eastern Honduras. Small clearings in the forest, although numerous in some areas, are not shown. Arrows indicate the direction of forest clearance. Large arrows represent areas under particularly heavy human colonization pressure. 
mountain trails. People in north-eastern Honduras do not travel far and know little about conditions away from their village areas, so I accepted only local information. In order to establish the reliability of the information given, I asked informants questions about tapirs: the colour and size, the size and shape of tracks, its close association with water, use of trails, the ability to crash through dense vegetation, its secretive and solitary nature, and a propensity to use 'latrines' and defecate in water. If they demonstrated a good knowledge of the animal, I accepted their information; if they did not, I rejected it. Over 70 interviews were conducted from informants in every part of the study area, except for the reportedly uninhabited Colon Mountains (Chalukian \& Bentley, 1995).

\section{Tapir signs}

I searched for tapir signs along the trail networks as I hiked through the mountains, but only once found tracks using this approach. In addition, I searched areas away from the trail networks; these were selected on the basis of interviews with local people. Typically, I hiked through an area engaging people in conversation and asking them if there were tapirs nearby. If they said there were, I would try to hire someone to show me the evidence (tracks, trails or faeces). Search routes and tapir sign locations were plotted on 1:50,000 topographic maps using a compass, a pedometer and natural landscape features as reference points.

\section{Numbers of tapirs}

No density surveys were conducted, so the number of tapirs in the study area was estimated by multiplying published density figures from other sites by the amount of tapir habitat in the study area. Following Matola $e t$ al. (1997), I used Fragoso's (1991) data (0.05 tapirs per sq $\mathrm{km})$ as a conservative estimate and Williams's (1994) data (0.24 tapir per sq $\mathrm{km}$ ) as a high estimate.

\section{Threats to tapirs}

Two potential threats to tapir persistence were investigated: forest clearance and hunting.

\section{Forest clearance}

Farmers, ranchers and townspeople were interviewed to reconstruct the history (the pace and pattern) of colonization, and the forces driving it. Interviews with farmers and ranchers and direct observation were used to determine the agricultural and pastoral economy and ecology. Clearings in the forest were designated as agricultural or pastoral and plotted on the maps.

\section{Hunting}

Information on hunting was obtained through interviews, and sites where tapirs were reported to have been killed were plotted on maps. Although several guides hunted as we searched for tapir signs, their quarry was smaller game (e.g. spider monkey Ateles geoffroyi, collared peccary Tayassu tajacu, paca Agouti paca) and I did not witness a tapir hunt.

\section{Results}

\section{Do tapirs survive in north-eastern Honduras?}

Interviews indicated that tapirs occur in the mountain rain forest throughout north-eastern Honduras, although the species's presence in the Colon Mountains remains unknown because no data were collected from that range. Twelve sets of tracks confirmed their presence in the Agalta and Carbon ranges and in the mountains between the Wampu and Aner rivers (Fig. 3). Searches confirmed anecdotal information that tapirs have disappeared from the Agalta and Guayape valleys, in the pine plantations and semi-deciduous woodlands on the lower mountain slopes, near roads, and in extensively cleared agricultural and pastoral areas. It is reported that they still use parts of the Sico Valley but the present rate of forest clearance makes it doubtful that tapirs will inhabit this valley for long because areas of suitable habitat are being severely altered.

\section{How many tapirs inhabit the study area?}

All rain forest was considered potential tapir habitat because water is abundant throughout and no elevation lies above the tapir's range (Emmons \& Freer, 1997). I estimated forest cover for the Agalta, Malacate, Carbon, Rio Tinto and Paya ranges at $1400-1500 \mathrm{sq} \mathrm{km}$, and for the Platano, Punta Piedra, Wampu/Aner, Patuca, Colon and Entre Rios ranges at $9000-10,000 \mathrm{sq} \mathrm{km}$, yielding a total of $10,400-11,500 \mathrm{sq} \mathrm{km}$ for north-eastern Honduras (Fig. 3). Using the density figures given above, this area of forest could support 520-2760 tapirs.

\section{Threats to tapir persistence}

Land clearing by subsistence farmers for planting maize, beans, yucca, sugar cane and coffee, and by ranchers for cattle raising are the main threats to tapir persistence in the study area, because these activities eliminate tapir habitat and the pattern of clearing is fragmenting the tapir population. Since the 1960s, an increasing flow of settlers have immigrated to the area and the pace of colonization continues unabated. The first wave of colonizers settled in the major valleys but 
later settlers moved further into the mountains, mostly along the larger streams and rivers. The main colonization fronts are along the Rio Blanco in the Patuca Mountains and north of the Wampu River in the southern part of the Rio Platano Biosphere Reserve (Fig. 3). All the land along the few roads has been completely cleared and settled, as has most of the land along the major rivers.

Although timber extraction is destroying tapir habitat in some parts of north-eastern Honduras (Chalukian \& Bentley, 1995), it does not appear to be a threat in the areas visited. Commercial logging is mainly restricted to harvesting trees from pine plantations, and I witnessed only selective logging of rain forest in the Paya Range.

Without tapir population trend data, it is impossible to assess the impact of hunting on tapirs in the long term. People reported hunting tapirs throughout northeastern Honduras and, based on anecdotal accounts, I estimate that a minimum of 30-40 tapirs were killed between 1989 and 1994 in the areas visited. However, the presence of tapir tracks in close proximity $(<1 \mathrm{~km})$ to human settlements (Flesher \& Ley, 1996) suggests that the current level of hunting does not pose an immediate threat to the species.

\section{Discussion}

The results of this preliminary investigation suggest that the forests of north-eastern Honduras support a major tapir population, making this a high-priority area for the conservation of this species. If the forest can be protected, a population of this size should be viable and have a good chance of long-term persistence, but if the present trend of forest clearing continues, tapir habitat will eventually be eliminated. The federal government has proposed seven conservation areas (Fig. 3), which encompass $10,481 \mathrm{sq} \mathrm{km}$ of the study area (essentially protecting the remaining forest), but farmers and ranchers have so far ignored the boundaries, or are unaware of them, and continue to clear reserve land. Land clearing along the Patuca and Wampu rivers threatens to fragment the contiguous Platano, Tawahka and Patuca reserves, and settlement along the Paulaya River has practically isolated these large reserves from the four smaller reserves in the Carbon, Malacate, Tinto and Agalta ranges. Furthermore, if the government goes through with plans to settle up to 20,000 families in the region's main river valleys (Matola et al., 1997), and to build roads along the Paulaya River, and between the Agalta and Malacate ranges, the fragmentation and isolation of the reserves is almost a certainty. As isolated entities, the reserves will probably be too small to support viable tapir populations, so if the area is to become an important site for tapir conservation, these threats to reserve connectivity will have to be addressed.

There are several possible reasons why hunting has not eliminated tapirs from settled areas as it has in many other Neotropical sites (Terwilliger, 1978; Eisenberg, 1989; IUCN, 1996). The primary reason may be that, as immigrants from areas long devoid of wildlife, the settlers have a weak hunting tradition. Very few of the people interviewed were dedicated hunters, and most hunting is incidental, with people pursuing game they encounter along the trails, in their fields or near their huts. The scarcity of hunting trails is another indication of the low priority people place on hunting. Furthermore, although Marineros (in Matola et al., 1997) found that tapirs were being hunted commercially in other parts of Honduras, no evidence of commercial hunting was found in the areas visited, so the financial incentive to hunt, which often leads to the over-exploitation of wildlife resources (Robinson \& Redford, 1991), was absent. In addition, the available hunting technology makes killing an animal the size of a tapir difficult. Most people hunt with dogs and a machete, and the few farmers who own firearms generally possess $0.22-$ calibre rifles better suited for killing smaller game. Finally, tapirs may still be found near settlements because most have only been established in the last 10-15 years and hunters have not yet had the time to extirpate the tapirs.

\section{Conclusion}

With so few areas left capable of supporting viable tapir populations, the forests of north-eastern Honduras deserve the immediate attention of the conservation community. Enough forest remains to give the tapir a good chance of long-term persistence, and if the reserve system is implemented, this area could prove a critical refuge for this ancient species. However, the government is under pressure to allocate land to landless peasants, which means that more forest is likely to be lost. But if the government can limit and manage human colonization, making sure that the designated reserve boundaries are respected and that forest corridors are left to connect the reserves, perhaps human and wildlife needs can be met. Honduras is a poor country and will need international help to finance this extensive conservation area, so the responsibility for preserving these forests lies with all of us. In addition to the tapir, these forests support significant populations of spider monkeys, mantled howler monkeys, jaguars, pumas, curassows, guans, scarlet macaws, king vultures and many other species, making this fascinating area a site of global importance. 


\section{Acknowledgements}

I would like to express special thanks to Sheryl Todd, Craig Downer and Dan Brooks for useful comments on the manuscript, to Doug Morris for help with the maps, to Ed Maxwell for company in the field, and to all the farmers who let me share their hearths and who told me about their lives in the forest.

\section{References}

Chalukian, S.C. \& Bentley, J.W. (1995) Cultural landscapes in Honduras: the Mosquitia. In Cultural Landscapes of Universal Value: Components of a Global Strategy (eds B. von Droste, H. Plachter and M. Rossler), pp. 202-209. Gustav Fisher Verlag and UNESCO, Stuttgart.

Eisenberg, J.F. (1989) Mammals of the Neotropics: The Northern Neotropics, vol. 1. University of Chicago Press, Chicago and London.

Emmons, L.H. \& Freer, F. (1997) Neotropical Rainforest Mammals-A Field Guide. University of Chicago Press, Chicago.

Flesher, K.M. \& Ley, E. (1996) A frontier model for landscape ecology: the tapir in Honduras. Environmental and Ecological Statistics, 3, 119-125.

Fragoso, J.M. (1991) The effect of hunting on tapirs in Belize. In Neotropical Wildilfe Use and Conservation (eds J. G. Robinson and K. H. Redford), pp. 154-162. University of Chicago Press, Chicago.

IUCN (1996) 1996 IUCN Red List of Threatened Animals. IUCN, Gland, Switzerland.

Matola, S., Cuaron, A.D. \& Rubio-Torgler, H. (1997) Status and action plan for Baird's tapir (Tapirus bairdii). In Status Survey and Conservation Action Plan-Tapirs (eds D.
M. Brooks, R. E. Bodmer and S. Matola), pp. 29-45. IUCN, Gland, Switzerland and Cambridge, UK.

Myers, N. (1986) Tropical deforestation and a mega-extinction spasm. In Conservation Biology: Science of Scarcity and Diversity (ed. M. E. Soule), pp. 394-409. Sinauer, Sunderland, Mass.

Robinson, J.G. \& Redford, K.H. (1991) Subsistence and commercial uses of wildlife in Latin America. In Neotropical Wildlife Use and Conservation (eds J. G. Robinson and K. H. Redford), pp. 6-23. University of Chicago Press, Chicago.

Terwilliger, V.J. (1978) Natural history of Baird's tapir on Barro Colorado Island, Panama Canal Zone. Biotropica, 10, 211-220.

Williams, K.D. (1994) The Central American tapir (Tapirus bairdii Gill) in northwestern Costa Rica. PhD thesis, Michigan State University.

\section{Biographical sketch}

Kevin Flesher is a graduate student in the Program in Ecology and Evolution at Rutgers University, New Jersey, USA. His research uses methodologies from the disciplines of ecology, anthropology and geography to study the role of multiple-use landscapes in the preservation of tropical biodiversity. Current research focuses on the interactions between subsistence farmers and wildlife in areas between reserves with the aim of defining landscape mosaics in which both human and wildlife needs can be met. $\mathrm{He}$ has conducted research in Central America, Brazil, South East Asia and West Africa. He is a member of the IUCN/SSC Tapir Specialist Group. 